\title{
LETTER
}

\section{3,4-Diaminopyridine may improve neuromuscular block during botulism}

\author{
Arnaud Friggeri ${ }^{1 *}$, Frédéric Marçon², Sandra Marciniak , Anne-Sophie Lemaire-Hurtel ${ }^{3}$, Abdoul Aziz Seydi $^{1}$, \\ Nacim Ammenouche ${ }^{1}$, Mélanie Levrard', Yazine Mahjoub ${ }^{1}$, Norik Airapetian', François Tinturier ${ }^{1}$, \\ Michel Petitjean ${ }^{4}$ and Hervé Dupont ${ }^{1}$
}

In September 2011, two outbreaks of botulism toxemia (toxin A) incriminating the same artisanal product were responsible for nine cases of botulism in France. Among these cases, three women (Cases 1, 2, and 3) aged 27, 29, and 23 years, respectively, were hospitalized in our ICU for mechanical ventilation support. They rapidly received a trivalent botulism antitoxin serum. Two weeks later, Case 3 passed a spontaneous breathing trial but needed new ventilator support 24 hours after extubation.

Association between respiratory failure and low compound muscle action potential (CMAP) amplitude measured at the forearm was reported in a study performed during a large outbreak in 2006 in Thailand [1]. CMAPs measured in the current Case 3 at the time of reintubation were $<50 \%$ of theoretical values.

Botulism could be considered a presynaptic myasthenia [2]. To reverse the effect of toxins, experimental models explored the effects of 3,4-diaminopyridine (3,4DAP) [3]. In Europe, 3,4-DAP is used to treat symptoms of Lambert-Eaton myasthenic syndrome [4,5].

We conducted a pilot study to evaluate the electrophysiological effects of 3,4-DAP (Clinical Trials Registration: NCT01441557). The clinical trial protocol was accepted by the local ethics committee and the French Agency for the Safety of Health Products (agence française de sécurité sanitaire des produits de santé). Patients signed an informed consent. Experiments were

\footnotetext{
*Correspondence: a_friggeri@yahoo.fr

${ }^{1}$ Réanimation polyvalente, Centre Hospitalier Universitaire d'Amiens, Place Victor Pauchet, Amiens F-80054, France

Full list of author information is available at the end of the article
}

conducted 21 days after the patients' admissions. Electrophysiological measures were collected before and after the oral administration of a single dose of 3,4-DAP (20 $\mathrm{mg}$ for Cases 1 and 2, $10 \mathrm{mg}$ for Case 3). The plasma concentration 90 minutes after administration was measured by liquid chromatography-tandem mass spectrometry. Cases 1 and 2 showed increase of CMAP amplitude after administration (Figure 1a) with a plasma concentration of $27 \mathrm{ng} / \mathrm{ml}$ and $18 \mathrm{ng} / \mathrm{ml}$, respectively. The absence of effect in Case 3 was associated with lower serum concentration $(5 \mathrm{ng} / \mathrm{ml})$. These results suggest that the intensity of paralysis was different between the cases and was clinically associated with the quantity of poisoned food ingested (from a single toast to the leftovers on a knife). These different intensities of paralysis may explain the discrepant effects observed as higher plasma concentration was not associated with better CMAP improvement. Interestingly, Case 2 who answered the best to the treatment was weaned earlier from mechanical ventilation.

In all cases, during the study period of 1 day, the CMAP amplitude concomitant to drug administration was higher than the later one, confirming the consistency of presynaptic block. Finally, weaning was successful at day 38, day 28, and day 35 in Cases 1, 2, and 3 , respectively, following a prolonged spontaneous T-piece trial.

Moreover, basic CMAPs at day 21 reflected the time to extubation (Figure 1b). In the perspective of bioterrorism, adjunctive treatment of botulism could be of a special interest in as much as stocks of antitoxin are limited. In this context, rapid onset of 3,4-DAP therapy may delay the evolution of paralysis to fatal respiratory failure. Although our results are encouraging, the observed effects of oral 3,4-DAP were modest and may be related to low blood concentration [5]. 


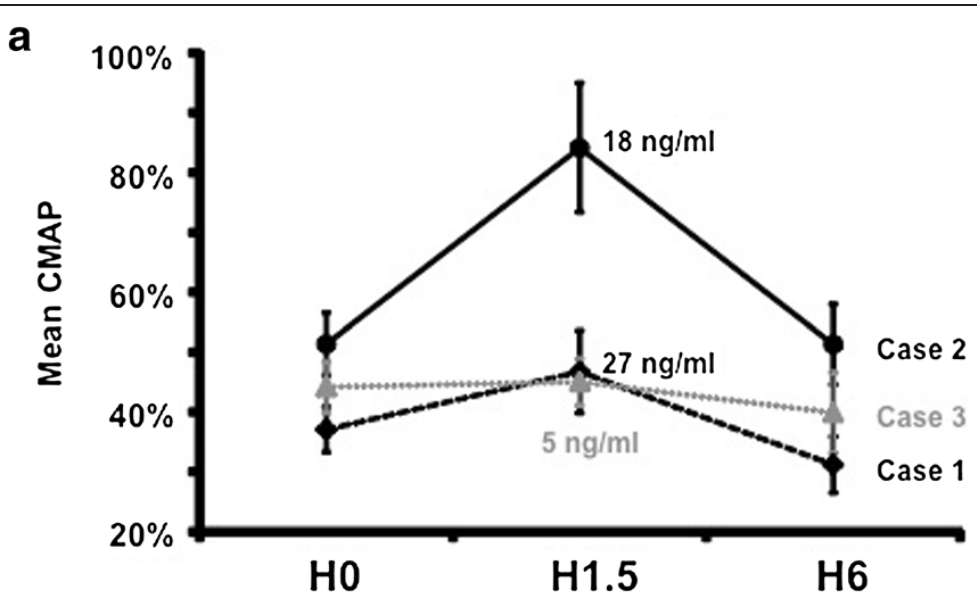

b

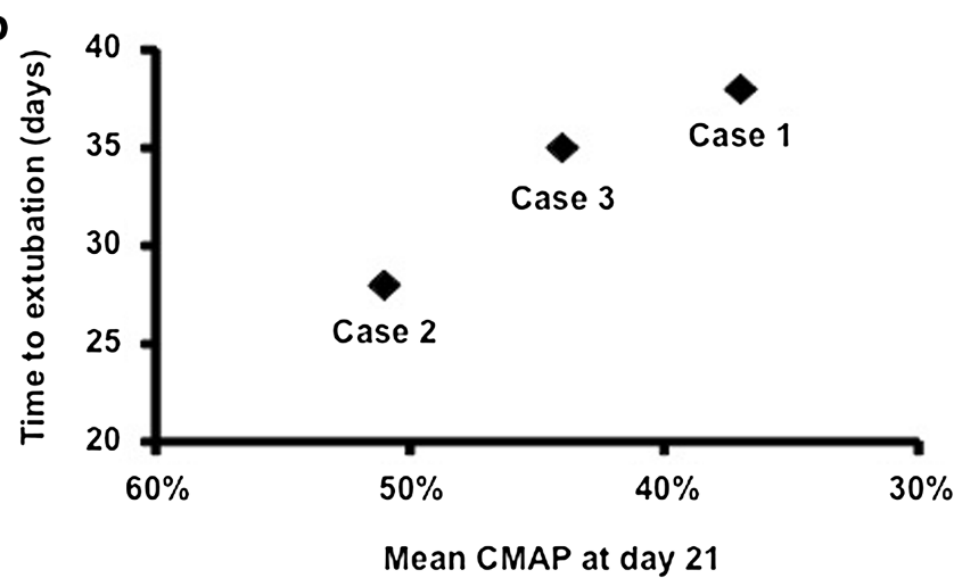

Figure 1 Low compound muscle action potential amplitudes. Surface electromyograms were recorded bilaterally from right and left abductor pollicis brevis (ABP) and abductor digiti minimi (ADM) muscles following median and ulnar nerves supramaximal stimulation at the wrist. (a) Low compound muscle action potential (CMAP) amplitude mean values expressed as a percentage of the lower limit of normality range of the right and left $\mathrm{APB}$ and the right and left $\mathrm{ADM} \pm 1$ standard error of the mean are represented according to timeline. No difference was observed between right and left sides. 3,4-Diaminopyridine (3,4-DAP) plasma concentrations are shown at +1.5 hours (H). Cases 1 and 2 received 20 mg 3,4-DAP, Case 3 received 10 mg (test dose). (b) Relation between time to extubation and CMAP mean values at day 21.

\section{Abbreviations}

3,4-DAP: 3,4-diaminopyridine; CMAP: Compound muscle action potential.

\section{Competing interests}

The authors declare that they have no competing interests.

\section{Acknowledgments}

The authors thank Stanislas Ledochowski for his advice.

\section{Author details}

'Réanimation polyvalente, Centre Hospitalier Universitaire d'Amiens, Place Victor Pauchet, Amiens F-80054, France. ${ }^{2}$ Pharmacie Centrale, Centre Hospitalier Universitaire d'Amiens, Place Victor Pauchet, Amiens F-80054, France. ${ }^{3}$ Laboratoire de pharmacologie et des gaz du sang, Centre Hospitalier Universitaire d'Amiens, Place Victor Pauchet, Amiens F-80054, France. ${ }^{4}$ Explorations Fonctionnelles du Système Nerveux, Centre Hospitalier Universitaire d'Amiens, Place Victor Pauchet, Amiens F-80054, France.

Published: 05 Sep 2013

\section{References}

1. Kongsaengdao S, Samintarapanya K, Rusmeechan S, Wongsa A, Pothirat C, Permpikul C, Pongpakdee S, Puavilai W, Kateruttanakul P, Phengtham U,
Panjapornpon K, Janma J, Piyavechviratana K, Sithinamsuwan P, Deesomchok A, Tongyoo S, Vilaichone W, Boonyapisit K, Mayotarn S, Piya-Isragul B, Rattanaphon A, Intalapaporn P, Dusitanond P, Harnsomburana P, Laowittawas W, Chairangsaris P, Suwantamee J, Wongmek W, Ratanarat R, Poompichate A, et al: An outbreak of botulism in Thailand: clinical manifestations and management of severe respiratory failure. Clin Infect Dis 2006, 43:1247-1256.

2. Zhang JC, Sun L, Nie QH: Botulism, where are we now? Clin Toxicol (Phila) 2010, 48:867-879.

3. Adler M, Capacio B, Deshpande SS: Antagonism of botulinum toxin Amediated muscle paralysis by 3,4-diaminopyridine delivered via osmotic minipumps. Toxicon 2000, 38:1381-1388.

4. McEvoy KM, Windebank AJ, Daube JR, Low PA: 3,4-diaminopyridine in the treatment of Lambert Eaton myasthenic syndrome. N Engl J Med 1989, 321:1567-1571.

5. Summary of 3,4-Diaminopyridine Characteristics. http://www.ema.europa.eu/ docs/en_GB/document_library/EPAR_-_Product_Information/human/ 001032/WC500069915.pdf.

$10.1186 / \mathrm{cc} 12880$

Cite this article as: Friggeri et al:: 3,4-Diaminopyridine may improve neuromuscular block during botulism. Critical Care 2013, 17:449 